\title{
Comparison of Radiological Findings of ChestX-Ray With Echocardiography in Determination of the Heart Size
}

\author{
Ali Biharas Monfared ${ }^{1}$; Shahnaz Agha Farajollah ${ }^{2,}$; Fahimeh Sabour ${ }^{2}$; Roya Farzanegan ${ }^{1}$; \\ Shahram Taghdisi ${ }^{2}$ \\ ${ }^{1}$ Tracheal Diseases Research Center, National Research Institute of Tuberculosis and Lung Diseases (NRITLD), Shahid Beheshti University of Medical Sciences, Tehran, IR Iran \\ ${ }^{2}$ Tehran Medical Sciences Branch, Islamic Azad University, Tehran, IR Iran \\ *Corresponding Author: Shahnaz Agha Farajollah, Tehran Medical Sciences Branch, Islamic Azad University, Tehran, IR Iran. Tel: +98-2188968627, Fax: +98-2188687966, E-mail: shfara- \\ jollah2@yahoo.com
}

Received: February 15, 2014; Revised: November 6, 2014; Accepted: December 9, 2014

\begin{abstract}
Background: Heart size is an important and effective parameter in chest X-ray (CXR) interpretation. Studies indicate that, especially in middle-aged men, increased cardiothoracic ratio(CTR) is associated with ischemic heart disease(IHD)and increased rate of morbidity and mortality. The CXR is the most common imaging examination of the heart.

Objectives: A good quality posterior-anterior(PA) chest radiograph is an important indicator of the cardiac size. Nowadays, CXR has given its place to more advanced approaches such as two-dimensional echocardiography. However, CXR is still more accessible and feasible for most of the physicians. This study was designed to compare the findings of CXR and echocardiography in determination of the heart size. Patients and Methods: This cross-sectional study was carried out from 2006 to 2007. A total of 197 patients entered the study. The cases had been undergone PACXR and 2-D echocardiography maximum within two days.

Results: Of participants, $24.9 \%$ had cardiomegaly according to the findings of CXR and 50.8\% based on echocardiography. There was a statistically significant difference between the mean size of Right Ventricular End Diastolic Diameter in the patients with cardiothoracic ratio $<50 \%$ and $\geq 50 \%(P=0.002)$ as well as Left Ventricular End Diastolic Diameter $(\mathrm{P}=0.023)$. Also, a statistically significant difference was seen between echocardiography and CXR findings with regard to determination of the heart size $(\mathrm{P}=0.003)$. Nonetheless, it is noteworthy that sensitivity and specificity of CXR findings in the diagnosis of cardiomegaly were $34 \%$, and $84.5 \%$, respectively.

Conclusions: CTR is the most common method of describing the heart size. Increased CTR in CXR is associated with poor prognosis, which is suggestive of importance and necessity of early diagnosis. Although CXR may not have the same diagnostic accuracy as echocardiography, its easy accessibility and high specificity in diagnosis of cardiomegaly is very helpful, which can play an important and a cost-benefit role, particularly in screening the enlarged heart size. Moreover, according to the statistics released by Medical Council of Iran, most of Iranian physicians are general practitioners and a few of them are cardiologist.
\end{abstract}

Keywords:Echocardiography; Thoracic Radiography; Enlarged Heart; Cardiomegaly

\section{Background}

Heart size is an important and helpful diagnostic parameter in chest X-ray (CXR); however, presence or absence of cardiomegaly in CXR depends on the interpreter's judgment (1). Even in one case, interpretations of different physicians could vary $(1,2)$. Naturally, some hypertrophic changes, without dilatation, occur in heart muscles by aging, which is often detectable by CXR (3-5). It is noteworthy that cardiomegaly is developed by different diseases, including valvular heart diseases, IHD, and cardiomyopathy as well as pericardial diseases.

Also, we should remember that increased CTR, especially in the middle-aged and elderly patients is correlated with IHD and increased rate of morbidity and mortality. Enlarged heart size is an independent predictor of death, and an increased CTR in CXR, irrespective of its etiology, is associated with poor prognosis in middle-aged patients. This issue is indicative of great importance and necessity of early diagnosis, especially in older patients (6-11).

In other words, according to Frishman et al. CXR screening paves the way for timely therapeutic interventions (6). In another study, it was revealed that CTR is as important as relative heart volume in the prediction of the mortality induced by IHD. In addition, only PA view of CXR is needed to determine CTR(8).

However, in the field of pediatric cardiology, Davidson's study showed that CTR has no correlation with echocardiographic findings and also Spiewak's study revealed that CTR in patients with repaired Tetralogy of Fallot can show atrial rather than ventricular dilatation, which could lead to false determination of ventricular size (12, 13).

Nowadays, various methods, with different efficiencies are applied for chest imaging and determination of the heart size. In this regard, echocardiography as an ad- 
Biharas Monfared A et al.

vanced method in the diagnosis of cardiac diseases has made CXR less important. Echocardiography is highly versatile, but operator dependent technique. Two-dimensional echocardiography gives direct imaging information about the anatomy and physiology of the heart, which identifying particular anatomical planes within the heart relies on the operator $(14,15)$. It is notable that two-dimensional echocardiography has to be performed by a cardiologist, whose access is quite difficult compared to a general practitioner.

Also, echocardiography is more expensive than CXR, and is not always successful as expected, especially in old and obese ones or in patients with increased lung volumes $(8,16)$. Above all, more than $75 \%$ of physicians in Iran are general practitioners and less than $25 \%$ are specialists (of course only a few of them are cardiologist). Furthermore, availability of medical instruments could play a significant role, especially at first line of diagnosis (11). Having considered the aforementioned issues, we designed this study to compare radiological findings of CXR with echocardiography in determination of the heart size and show the value of standard PA CXR as a cost-effective and applicable approach in diagnosis of the heart size. However, determination of the heart size in radiography could be affected by different factors, including the shape and the size of thorax, patient's position at imaging, air in the lungs and respiratory diseases. Sometimes heart enlargement, especially in its mild or average status is overlooked. Accurate differentiation of the normal heart size from its abnormal size could be difficult. Therefore, different diagnoses among physicians are inevitable (1).

\section{Objectives}

A good quality posterior-anterior (PA) chest radiograph is an important indicator of the cardiac size. Nowadays, CXR has given its place to more advanced approaches such as two-dimensional echocardiography. However, CXR is still more accessible and feasible for most of the physicians. This study was designed to compare the findings of CXR and echocardiography in determination of the heart size.

\section{Patients and Methods}

This cross-sectional study was carried out in one specialized state-run hospital in Tehran, Iran, from June 2006 to July 2007. The cases were patients who had undergone echocardiography and PA CXR maximum within two days. In fact, patients were first supposed to undergo both echocardiography and CXR in one day, but due to unstable condition of some patients in cardiology ward, we finally decided to study patients who had undergone both procedures in two consecutive days. Additionally, patients who took portable CXR were excluded from the study, because it is not standard in determination of the heart size. The sample size was calculated with an expect- ed power of $90 \%$.

A total of 225 patients, admitted to the cardiology ward, were selected by random sampling method, and finally 197 of them met the inclusion criteria. Patient's heart size was determined by 2-D echocardiography and PA CXR. We used CTR as the most common method of describing the heart size (17).

The standard PA CXR (taken by analog calibrated Toshiba system with this criteria: Beam limiting device, model TF-6TL-6, input 1-phase 50/60Hz AC12V, max input power 100VA, max tube voltage $150 \mathrm{KV}$, filtration $1.2 \mathrm{~mm}$ ) was taken on deep inspiration which was interpreted only by one radiologist and CTR was recorded as shown in Figure 1 , which is less than $50 \%$ in normal condition $(6,11,17)$.

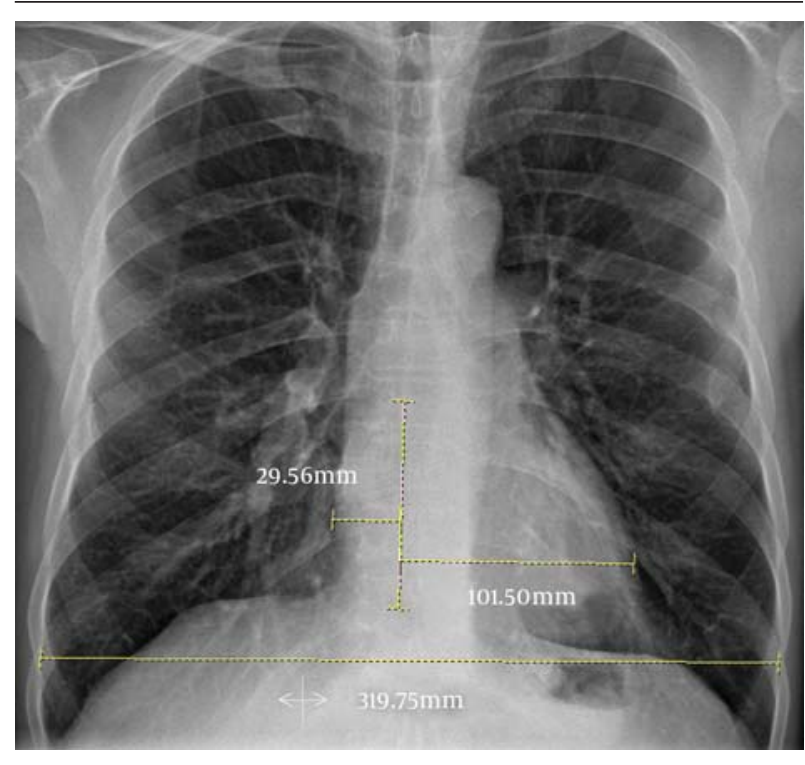

Figure 1. Determination of the Heart Size on the Standard PA CXR

One cardiologist carried out the echocardiography (GE, Vingmed4, with mode 2-D, parasternal and 4 chambers). RVEDD and LVEDD were used to measure the echocardiographic size of the heart. They were determined by 2-D echocardiography and in normal condition are less than $25 \mathrm{~mm}$ and $55 \mathrm{~mm}$, respectively (18-22). In this study, adequate physical activity for adults has been defined according to WHO recommendations (23).

Ethics Committee of Islamic Azad University, Tehran Medical Sciences Branch approved this study with the ethical number 3802. Although, there was not any intervention in this study, we considered "the protection code of human subjects in medical research" of Iran's Ministry of Health and Medical Education. Because we used the patients' records, all the information was kept confidential (24).

SPSS version 16 was used to analyze the extracted data, and chi-square test to assess qualitative variables such as heart enlargement in echocardiography and radiography, and the mean of RVEDD and LVEDD in the noncardiomegal and the cardiomegal cases (according to the 
CXR findings of a radiologist) were compared with MannWhitney $\mathrm{U}$ test. The level of significance was considered less than 0.05 .

\section{Results}

Ninety-nine patients (50.3\%) were male and 98 (49.7\%) were female. The mean age was $57.47 \pm 10.75$ years, ranged from 34 to 86 years. One hundred and fifty patients were non-smoker and 47 were smoker. The median of packyear in smokers was $18 \mathrm{p} / \mathrm{y}$ ranged from 1 to $60 \mathrm{p} / \mathrm{y}$. Fortyeight patients (24.4\%) had acceptable physical activity according to WHO recommendations, whereas 149 (75.6\%) did not. The history of IHD and hypertension were seen in $52.3 \%$ and $38.6 \%$ of the patients, respectively.
According to CXR and echocardiography, 49 (24.9\%) and $100(50.8 \%)$ patients had cardiomegaly, respectively. All variables were compared between cardiomegal and noncardiomegal patients based on CXR and echocardiography (Tables 1 and 2).

Overall, there was a significant difference between the heart size determined by echocardiography and CXR $(\mathrm{P}=$ 0.003). Additionally, our study revealed a statistically significant difference between CTR in IHD patients and CTR in non-IHD patients $(\mathrm{P}=0.02)$.

Moreover, sensitivity and specificity of CXR in diagnosis of cardiomegaly were $34 \%$ and $84.5 \%$, respectively, which could be helpful in screening cardiomegaly. In fact, when PA view of CXR indicates absence of heart enlargement, to a great extent, the same result can be seen in echocardiography (Table 3 ).

\begin{tabular}{|c|c|c|}
\hline & $\begin{array}{l}\text { The Patients With Cardiomegaly According } \\
\text { to Chest X-Ray }(n=49)\end{array}$ & $\begin{array}{l}\text { The Patients With Cardiomegaly According to } \\
\text { Echocardiography }(\mathbf{n}=100)\end{array}$ \\
\hline Age, $y^{b}$ & $62.41(43-82)$ & $59.00(34-85)$ \\
\hline \multicolumn{3}{|l|}{ Gender $^{\mathrm{a}}$} \\
\hline Male & $12(24)$ & $52(52)$ \\
\hline Female & $37(76)$ & $48(48)$ \\
\hline RVEDD, mm & $25(18-40)$ and IQR $=7 \mathrm{~b}$ & $27.32(18-40)^{\mathrm{C}}$ \\
\hline LVEDD, $\mathbf{~ m m}^{\mathrm{c}}$ & $54(36-70)$ and $\mathrm{IQR}=13$ & $56(35-70)$ and $\mathrm{IQR}=7$ \\
\hline History of IHD ${ }^{\text {a }}$ & $33(67)$ & $55(55)$ \\
\hline History of HTN ${ }^{\text {a }}$ & $29(59.2)$ & $41(41)$ \\
\hline Smoking ${ }^{a}$ & $6(12)$ & $20(20)$ \\
\hline Suitable physical activity ${ }^{a}$ & $10(20)$ & $23(23)$ \\
\hline
\end{tabular}

\begin{tabular}{|c|c|c|}
\hline & $\begin{array}{l}\text { Patients With Normal Heart According to } \\
\text { Chest X-Ray }(n=148)\end{array}$ & $\begin{array}{l}\text { Patients With Normal Heart According to } \\
\text { Echocardiography }(\mathbf{n}=97)\end{array}$ \\
\hline Age, y & $55.00(34-86)$ and $\mathrm{IQR}=15^{\mathrm{b}}$ & $55.90(34-86)^{\mathrm{c}}$ \\
\hline \multicolumn{3}{|l|}{ Gender $^{\mathrm{a}}$} \\
\hline Male & $87(59)$ & $47(48)$ \\
\hline Female & $61(41)$ & $50(52)$ \\
\hline RVEDD, $\mathbf{m m}^{\mathrm{b}}$ & $24(15-37)$ and $\mathrm{IQR}=5$ & $23(15-25)$ and $I Q R=3$ \\
\hline LVEDD, mm $^{\mathrm{b}}$ & $49(34-63)$ and $\mathrm{IQR}=11$ & $45(34-55)$ and $\mathrm{IQR}=8$ \\
\hline History of IHD ${ }^{\text {a }}$ & $70(47)$ & $48(49)$ \\
\hline History of HTN ${ }^{\text {a }}$ & $47(32)$ & $35(36)$ \\
\hline Smoking ${ }^{\mathrm{d}}$ & $41[16(1-60)]$ and $\mathrm{IQR}=21.5$ & $27[15(1-60)]$ and $I Q R=20$ \\
\hline Suitable physical activity ${ }^{a}$ & $38(26 \%)$ & $25(26 \%)$ \\
\hline
\end{tabular}

a Data are presented as No. (\%).

b Median, range and interquartile range (IQR).

c Mean (range).

$\mathrm{d}$ The number of smokers [median, range and interquartile range(IQR) of $\mathrm{P} / \mathrm{Y}$ in smokers]. 
Biharas Monfared A et al.

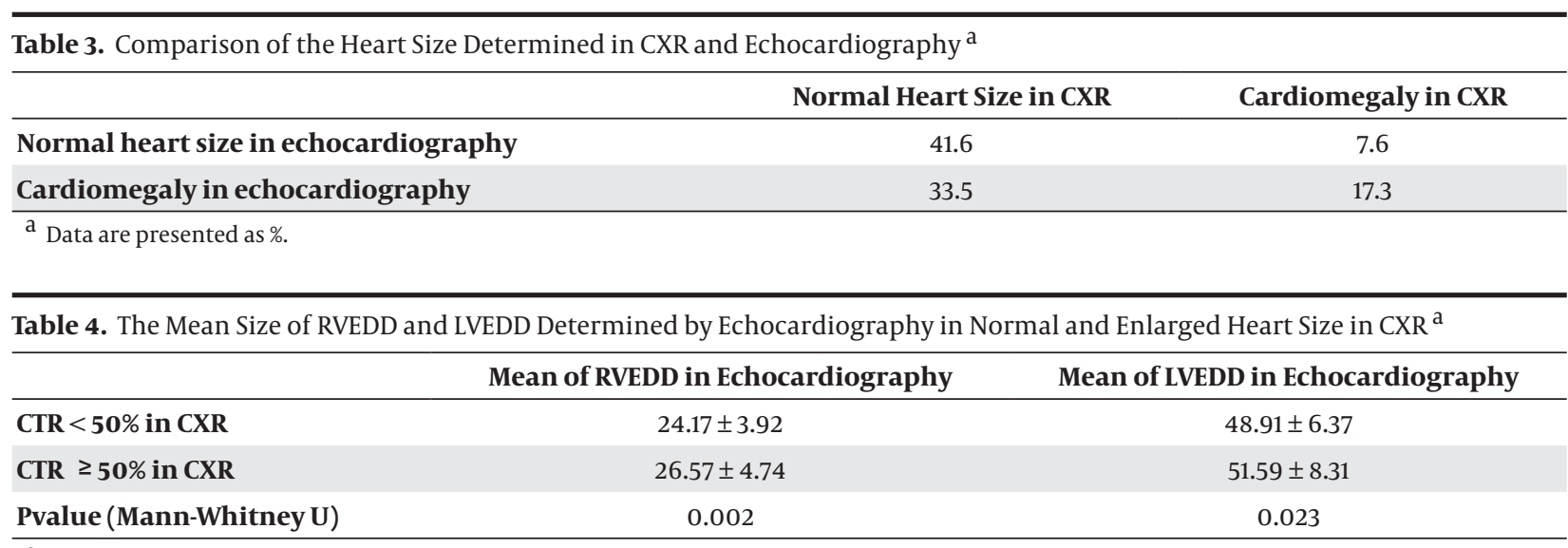

${ }^{\mathrm{a}}$ Data are presented as Mean \pm SD.

The median of LVEDD and RVEDD were $50 \mathrm{~mm}$ (34-70 $\mathrm{mm}$ ) and $24 \mathrm{~mm}(15-40 \mathrm{~mm})$, respectively. Additionally, the means were compared in normal (CTR $<50 \%$ ) and enlarged (CTR $\geq 50 \%$ ) heart size in CXR with MannWhitney U-test, which demonstrated a statistically significant difference between them (P value $<0.05$, Table $4)$.

\section{Discussion}

Cardiomegaly is an independent prognostic factor for mortality, and increased CTR, which (regardless of its etiology) is associated with poor prognosis in older patients. However, our study showed a significant difference between CTR in IHD and non-IHD patients ( $\mathrm{P}=$ 0.02).

It should be noted that cardiomegaly found in CXR correlates with 1.84 times increase in mortality. Also LV hypertrophy determined by echocardiography is associated with 1.5 to 4 times increase in mortality, which is indicative of great importance and necessity of early diagnosis, especially in old or middle-aged patients (6, $8,16)$. Cardiomegaly could result in mortality due to some mechanisms such as higher oxygen need by larger ventricular mass, fatal ventricular arrhythmias, and endothelial dysfunction (25-27). LV size as an independent factor can be an indicator of cardiovascular diseases, which could be estimated by CTR $(10,16,28)$.

Jung et al. showed that CTR in the detection of pathologic End Diastolic Volume Index and Ejection Fraction had $77.3 \%$ and $57.4 \%$ sensitivity, $79.3 \%$ and $80.8 \%$ specificity, and $78.9 \%$ and $72.5 \%$ accuracy, respectively. They concluded that CTR in standard CXR can play an important role in screening and follow-up of patients with cardiac disease (29). Furthermore, in Nakamori's study, CTR was considered as the most effective measurement in CXR to detect cardiomegaly, which has the minimum false positive in comparison with transverse and longitudinal diameter of the heart and lungs (1). Also, Perez et al. designed a study on patients with Chagas disease and concluded that abnormal radiological findings in PA CXR in comparison with echocardiography had 50\% sensitivity and $80.5 \%$ specificity (30). In another study, although single-dimension echocardiography was shown to be able to differentiate left ventricular hypertrophy from dilatation, it did not show lateral or inferior enlargement of the heart. In other words, single-dimension echocardiography does not accurately determine size of the right ventricle (31).

On the contrary, in another study the clinical value of cardiac volume determined by CXR, as a parameter for left ventricular (LV) systolic function, was considered low and dependent on the cause of heart enlargement, and accuracy of CXR in diagnosis of cardiomegaly was seen to be significantly lower than that of echocardiography. Also Clark et al. demonstrated that echocardiography and radionuclide ventriculography can depict the degree of LV dysfunction much better than the CXR (32). In our study, there was a significant difference in terms of the heart size in echocardiography and CXR (P $=0.003$ ). However, this issue was predictable from the beginning steps of the study, and we did not mean to underestimate the value of echocardiography, but one of the objectives of this study was to clarify that this diagnostic tool should be used at a proper stage of approaching the patient (not for example screening).

Thus, this study is designed to clarify to what extent CXR can be reliable in the detection of cardiomegaly. The result indicates that CXR does not have high degree of sensitivity (34\%), despite its specificity (84.5\%), which in Jung study were $48.8 \%$ and $93.6 \%$ respectively. These findings are quite compatible with our findings. This slight difference between these two studies seems to be due to the study method. In Jung study, besides PA view, lateral view was also taken, but in our study the PA view was merely taken to lower the risk of X-ray exposure and also to be able to compare this study with other studies (29).

In other words, when PA view of CXR indicates absence of heart enlargement, to a great extent, the same result can be seen in echocardiography, which is suggestive of the remarkable role of CXR in screening.

Finally, CXR as a diagnostic procedure is not as strong 
and accurate as echocardiography, but its accessibility and high degree of specificity in diagnosis of cardiomegaly would be very beneficial for the majority of medical practitioners, especially in screening process and patient detection.

Moreover, if CTR has increased in comparison with the previous CXR, it could be more important than merely knowing the CTR without comparison with other CXRs. Consequently, it seems that a research project is on demand in which patients undergo both echocardiography and CXR at a regular and constant follow up, so that these two procedures could be compared in the long run and their relationship with prognosis of cardiovascular patients be evaluated.

\section{Acknowledgements}

We are very grateful to the head nurse of cardiology ward of Javaheri Hospital, Mrs Leila Omidvar, for her sincere cooperation in data collection.

\section{Authors' Contributions}

Dr Ali Biharas Monfared gathered most of the data, analyzed them, and wrote the first draft, which was his dissertation. Dr Shahnaz Agha Farajollah revised the manuscript and advised the other authors to write the manuscript. Dr Fahimeh Sabour revised and gathered the data. Dr Roya Farzanegan revised the manuscript. Dr Shahram Taghdisi technically revised the manuscript as a cardiologist.

\section{References}

1. Nakamori N, Doi K, MacMahon H, Sasaki Y, Montner S. Effect of heart-size parameters computed from digital chest radiographs on detection of cardiomegaly. Potential usefulness for computer-aided diagnosis. Invest Radiol.1991;26(6):546-50.

2. Manninen H, Remes J, Partanen K, Tynkkynen P, Mykkanen L, Laakso M, et al. Evaluation of heart size and pulmonary vasculature. Conventional chest roentgenography and image intensifier photofluorography compared. Acta Radiol. 1991;32(3):226-31.

3. Levy D, Anderson KM, Savage DD, Kannel WB, Christiansen JC, Castelli WP. Echocardiographically detected left ventricular hypertrophy: prevalence and risk factors. The Framingham Heart Study. Ann Intern Med. 1988;108(1):7-13.

4. Geokas MC, Lakatta EG, Makinodan T, Timiras PS. The aging process. Ann Intern Med. 1990;113(6):455-66.

5. Ensor RE, Fleg JL, Kim YC, de Leon EF, Goldman SM. Longitudinal chest x-ray changes in normal men. J Gerontol.1983;38(3):307-14.

6. Frishman WH, Nadelmann J, Ooi WL, Greenberg S, Heiman M, Kahn S, et al. Cardiomegaly on chest x-ray: prognostic implications from a ten-year cohort study of elderly subjects: a report from the Bronx Longitudinal Aging Study. Am Heart J. 1992;124(4):1026-30.

7. Potter JF, Elahi D, Tobin JD, Andres R. Effect of aging on the cardiothoracic ratio of men. JAm Geriatr Soc. 1982;30(6):404-9.

8. Hemingway H, Shipley M, Christie D, Marmot M. Cardiothoracic ratio and relative heart volume as predictors of coronary heart disease mortality. The Whitehall study 25 year follow-up. Eur Heart J.1998;19(6):859-69.

9. Lavie CJ, Milani RV, Patel D, Artham SM, Ventura HO. Disparate effects of obesity and left ventricular geometry on mortality in 8088 elderly patients with preserved systolic function. Postgrad Med. 2009;121(3):119-25.
10. Artham SM, Lavie CJ, Milani RV, Patel DA, Verma A, Ventura HO. Clinical impact of left ventricular hypertrophy and implications for regression. Prog Cardiovasc Dis. 2009;52(2):153-67.

11. Screaton N. The cardiothoracic ratio--an inaccurate and outdated measurement: new data from CT. Eur Radiol. 2010;20(7):15978.

12. Davidson A, Krull F, Kallfelz HC. Cardiomegaly--what does it mean? A comparison of echocardiographic to radiological cardiac dimensions in children. Pediatr Cardiol. 1990;11(4):181-5.

13. Spiewak M, Malek LA, Biernacka EK, Kowalski M, Michalowska I, Hoffman P, et al. Cardiothoracic ratio may be misleading in the assessment of right- and left-ventricular size in patients with repaired tetralogy of Fallot. Clin Radiol. 2014;69(7):e1-8.

14. Nakamori N, Doi K, Sabeti V, MacMahon H. Image feature analysis and computer-aided diagnosis in digital radiography: automated analysis of sizes of heart and lung in chest images. Med Phys. 1990;17(3):342-50.

15. Sutton D. Textbook of Radiology and Imaging.: Churchill Livingstone; 2003.

16. Schlett CL, Kwait DC, Mahabadi AA, Bamberg F, O'Donnell CJ, Fox CS, et al. Simple area-based measurement for multidetector computed tomography to predict left ventricular size. Eur Radiol. 2010;20(7):1590-6.

17. Hasan MA, Lee SL, Kim DH, Lim MK. Automatic evaluation of cardiac hypertrophy using cardiothoracic area ratio in chest radiograph images. Comput Methods Programs Biomed. 2012;105(2):95-108.

18. Parfrey PS, Collingwood P, Foley RN, Bahrle A. Images in nephrology. Left ventricular disorders detected by M-mode echocardiography in chronic uraemia. Nephrol Dial Transplant. 1996;11(7):1328-31.

19. Lang RM, Bierig M, Devereux RB, Flachskampf FA, Foster E, Pellikka PA, et al. Recommendations for chamber quantification: a report from the American Society of Echocardiography's Guidelines and Standards Committee and the Chamber Quantification Writing Group, developed in conjunction with the European Association of Echocardiography, a branch of the European Society of Cardiology. J Am Soc Echocardiogr. 2005;18(12):1440-63.

20. Schiller NB, Shah PM, Crawford M, DeMaria A, Devereux RB, Feigenbaum $\mathrm{H}$, et al. Recommendations for quantitation of the left ventricle by two-dimensional echocardiography. American Society of Echocardiography Committee on Standards, Subcommittee on Quantitation of Two-Dimensional Echocardiograms. J Am Soc Echocardiogr. 1988;2(5):358-67.

21. Triulzi M, Gillam LD, Gentile F, Newell JB, Weyman AE. Normal Adult Cross-Sectional Echocardiographic Values: Linear Dimensions and Chamber Areas. Echocardiography. 1984;1(4):403-26.

22. Foale R, Nihoyannopoulos P, McKenna W, Kleinebenne A, Nadazdin A, Rowland E, et al. Echocardiographic measurement of the normal adult right ventricle. Br Heart J. 1986;56(1):33-44.

23. W.H.O . Global Recommendations on Physical Activity for Health.: World Health Organization; 2011.

24. Karoubi MT, Akhondi MM. How Does Iranian's Legal System Protect Human Vulnerability and Personal Integrity in Medical Research? Avicenna J Med Biotechnol. 2011;3(2):51-9.

25. Houghton JL, Frank MJ, Carr AA, von Dohlen TW, Prisant LM. Relations among impaired coronary flow reserve, left ventricular hypertrophy and thallium perfusion defects in hypertensive patients without obstructive coronary artery disease. J Am Coll Cardiol.1990;15(1):43-51.

26. McLenachan JM, Henderson E, Morris KI, Dargie HJ. Ventricular arrhythmias in patients with hypertensive left ventricular hypertrophy. N Engl J Med.1987;317(13):787-92.

27. Treasure CB, Klein JL, Vita JA, Manoukian SV, Renwick GH, Selwyn AP, et al. Hypertension and left ventricular hypertrophy are associated with impaired endothelium-mediated relaxation in human coronary resistance vessels. Circulation. 1993;87(1):86-93.

28. Lavie CJ, Patel DA, Milani RV, Ventura HO, Shah S, Gilliland Y. Impact of echocardiographic left ventricular geometry on clinical prognosis. Prog Cardiovasc Dis. 2014;57(1):3-9.

29. Jung G, Landwehr P, Schanzenbacher G, Faeber B, Lackner K. 
[Value of thoracic radiography in the assessment of cardiac size. A comparison with left ventricular cardiography]. Rofo. 1995;162(5):368-72.

30. Perez AA, Ribeiro AL, Barros MV, de Sousa MR, Bittencourt RJ, Machado FS, et al. Value of the radiological study of the thorax for diagnosing left ventricular dysfunction in Chagas' disease. Arq Bras Cardiol. 2003;80(2):208-13.
31. Cooperberg PL, Chahlauoi J, Khan N, O'Donovan M, Winsberg F. Estimation of cardiac chamber size by routine chest radiography and echocardiography. Radiology. 1976;119(1):193-8.

32. Clark AL, Coats AJ. Unreliability of cardiothoracic ratio as a marker of left ventricular impairment: comparison with radionuclide ventriculography and echocardiography. Postgrad Med J. 2000;76(895):289-91. 